\title{
University Student Views on The Impact of COVID-19 Pandemic on Their University Life and Education in Sri Lanka.
}

\author{
KDS Sandarenu ${ }^{\mathrm{a}, *}$ \\ ${ }^{\mathrm{a}}$ kdssandarenu@kdu.ac.lk \\ Kotelawala Defence University, Faculty of Allied Health Sciences, Werahera, 10290, Sri Lanka
}

\begin{abstract}
The corona virus COVID-19 pandemic is a world disaster. The effect on all facets of life, including education, is primarily negative. This study examined its impact on university student life and education in order to support future students by using the experience of current university students during this pandemic period.
\end{abstract}

A novel self-administered questionnaire was developed to explore relevant demographics and the COVID-19 impact on university life and education using both quantitative and qualitative tools with expert and peer collaboration. The questionnaire link was shared with students as a google form link via their universities to be completed over a 4-week period.

A total of 249 students from five universities in Sri Lanka (78\% female, 71\% aged 22-25 years) responded. Virtual learning methods have been adopted by all participating universities during the pandemic. In view of its flexibility and comfort, the students appreciated some of the aspects of the new mode, the facility for access to recorded material for revision and savings incurred by studying from home. However, from technical aspects and teacher aspects, many frustrations were identified, including poor quality, poor scheduling, and problems in the consistency of the tests with the material taught. The effectiveness of virtual learning has been significantly hampered by digital poverty. In addition, poor contact between teachers and peers created a lot of tension. The overnight change to virtual education with a lack of experience was difficult for many students to deal with. Universities need to take immediate proactive steps to change the strategies of virtual education, resolving issues of digital poverty is likely to greatly increase the effectiveness of virtual learning.

Keywords: COVID-19 pandemic; Virtual learning; Digital poverty; Efficacy; Drawbacks

\section{Introduction}

The corona virus, COVID-19 pandemic is a world disaster. It has affected all 'norms' of life economically and socially, including health and well-being. The impact is mostly detrimental. These negative trends must be learnt proactively and prospectively to enable us to mitigate and provide solutions and return life back to the undefined 'new normal' minimizing long lasting damage.

Education had a major impact due to the social distancing and the strict lock-down laws during the pandemic. Following the COVID-19 pandemic, schools, colleges, and universities all closed in order to prevent further infection and the further spread of the disease. Students have reported anxiety, depression, and mood swings due to the physical closing of schools, colleges, and universities (Son, Hegde, Smith, and Wang, 
2020). Students' social contact has been interrupted due to COVID-19, and this has influenced their family life. Students were virtually forgotten amidst prioritizing needs of essential services. Students' face-to-face learning had become non-existent. Lives, friendships, costs of living, personal incomes all became unpredictable. Also, the process of learning dramatically changed in a single day doing away with various support programs that had previously been in place. The majority of studying, training, teaching, and testing has become 'virtual'. These student impacts can have a lasting influence on their academic performances and advancements. So, it follows that academic institutions should bring in steps to help students rebound from the effects of COVID-19. This study is designed to explore the student experiences, general well-being, concerns, and their aspirations and suggestions for improvement in Sri Lanka.

\section{Methods}

This study was a survey-based study that is planned to launch fully online. Participants was current university students of Sri Lanka. A self-administered questionnaire was used as the data collection tool. Some of the questions relating to the student and their experiences, a 360-degree view of what has happened to their education and well-being, and how they are coping with the changes, looking at both the positives and negatives. It took 15-20 minutes to answer the questionnaire. There was no physical meet between the investigators and participants. All the information sheets, consent forms and the questionnaires were shared online among the participants through the respective collaborators of the universities.

An anonymized online survey was designed in English using Google forms. This assessment aimed to produce useful measurements with specific and observable results. It included a novel questionnaire developed in collaboration to assess the impact of COVID-19 on students, using open innovative questions in support of the expectations of this project including student suggestions for improvement and aspirations for the future. In addition to the demographics data such as age, gender, and the year of study in university, and course, details on support available to them (e.g., family, bursaries, accommodation) that may influence their wellbeing were obtained. All questions were ratified by the research collaborators. The student participation was voluntary, and all responses were anonymized. There was no use of any personal identifiable information such as name, date of birth or postal address.

Ethical approval was obtained from the Ethical Review Committee of Faculty of Medicine, Kotelawala Defence University (RP/2020/28). The full questionnaire was sent as a google form link to assist this process. All five participating universities shared the aforesaid link on an agreed date via an institutional group email that contained the study link for the questionnaire saved in google forms (Travis, 2010). Data collection closed after 4 weeks in early December 2020.

\subsection{Inclusion criteria:}

Current university student at any level of university education in Sri Lanka.

\subsection{Exclusion criteria:}

Non consent. 


\subsection{Questionnaire}

The questionnaire was subcategorized into three domains.

- Domain 1- The Information Letter, Consent, and Demographics

This included the participant invitation letter, consent form, a request for a fake ID and questions on demographics.

- $\quad$ Domain 2 - Impact of COVID-19 on University Life

This section of the questionnaire explored how COVID-19 has affected students, socially and financially and the different challenges they are facing.

- Domain 3 - Impact of COVID-19 on University Education

This section gathered the students' opinions on both the positive and negative aspects of new modes of 'virtual' learning and possible improvements.

\section{Data analysis}

The participant answers for open-ended questions were employed for the qualitative analysis. These questions considered the various positive and negative implications of a modern "virtual" mode of learning, the effect of virtual lectures and assessments, and ways participants felt could be improved. The questionnaire data was analyzed, compared, and grounded using Grounded Theory (Strauss and Corbin, 1998). Codes have been conceptualized into categories (themes). To improve the understanding of the theme, the sub-categories that emerged were listed and quotations from some written comments were listed.

\section{Results}

\subsection{Quantitative study}

\subsubsection{Demography}

A total of 249 students responded from five universities in Sri Lanka including both public and private universities. They were from a range of courses including Medicine, Dentistry, Pharmacy, Medical laboratory science, Radiology, Biomedical science, finances, law and more. Their age groups and year of study distributions are shown in Figure 1 and Figure 2, respectively. 


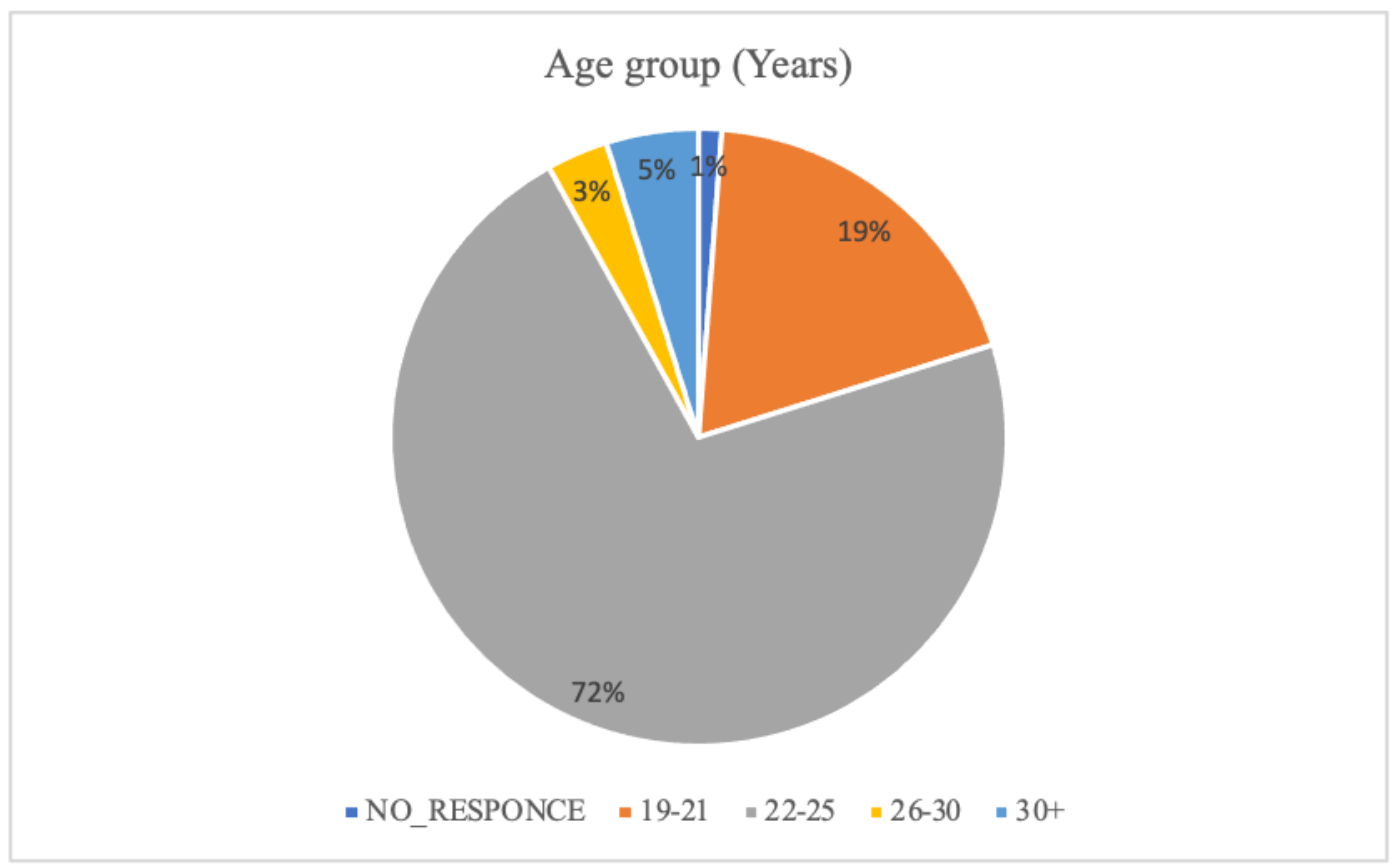

Fig. 1. Age distribution of the participants

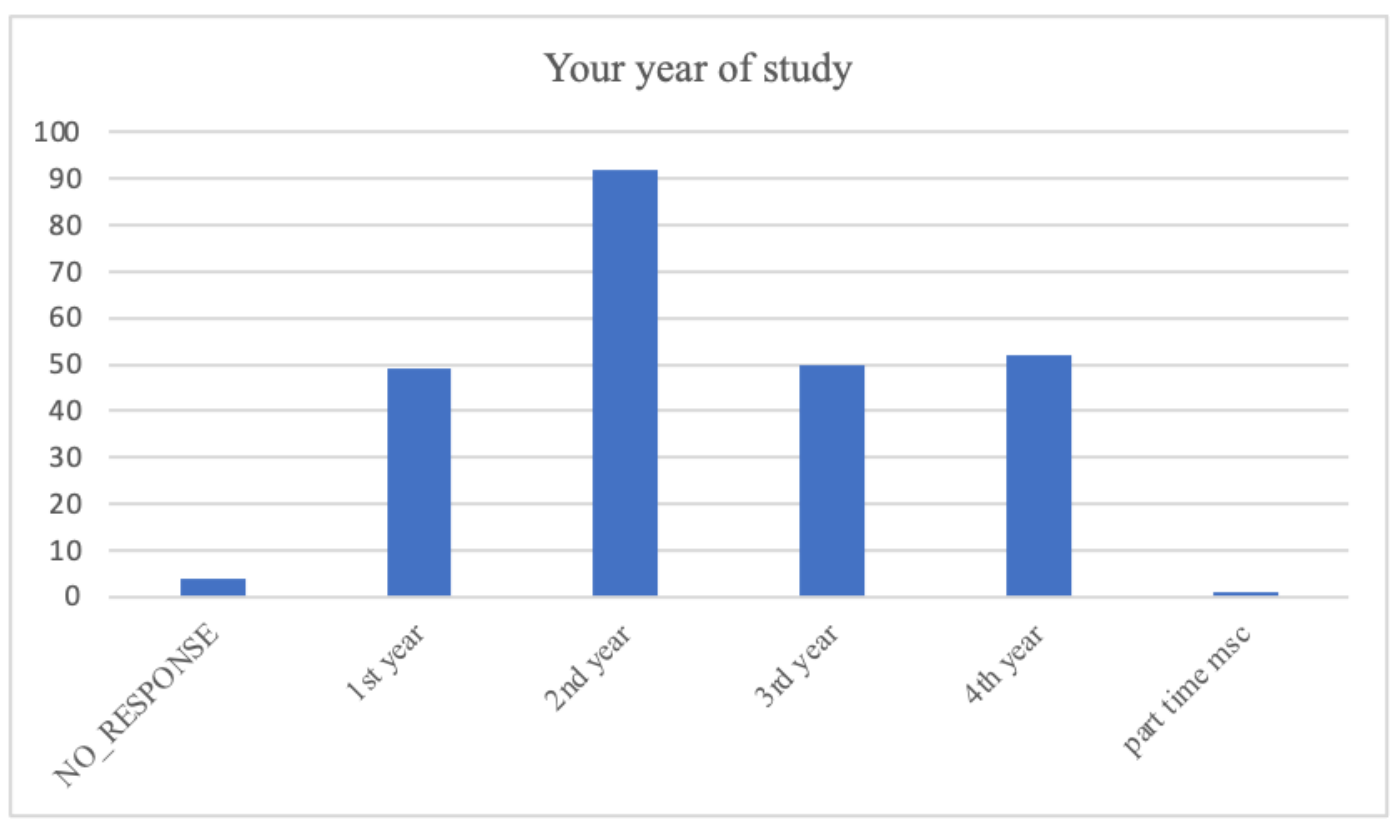

Fig. 2. Year of study of the participants 


\subsubsection{Impact on university life}

The participating students represent both state universities (e.g., University of Sri Jayawardhanepura, University of Ruhuna) and private universities (e.g., NSBM Green University) in Sri Lanka. In that most of the students $(68.5 \%)$ were family funded while $18.9 \%$ of the participants were self-funded. Their accommodation was classified as 'private' (home and rented) and 'shared' (university halls, boarding houses with shared facilities). The accommodation preferences of students changed towards 'private' during the pandemic (Figure 3).

\section{Accomodation during COVID-19 pandemic}

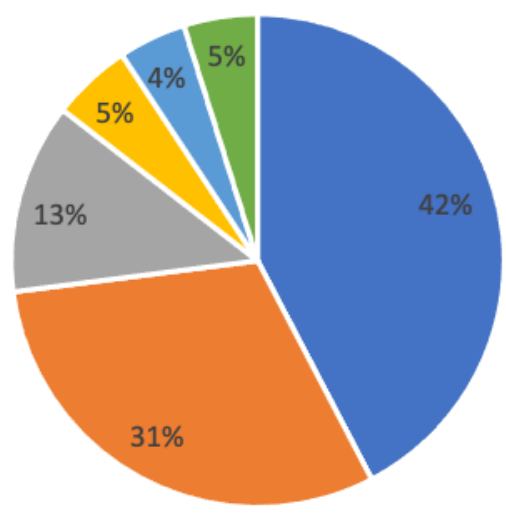

$$
\begin{array}{ll}
\text { - daily commuter from home } & \text { - resident in a boarding with other students } \\
\text { - resident in own accomodation } & \text { " resident in private rented accommodation } \\
\text { - NO_RESPONSE } & \text { - university hostel }
\end{array}
$$

Fig. 3. Student accommodation during pandemic time

\subsubsection{Impact on student education}

Many students (47\% of respondents) have responded that the new standard of education they are getting is poor in terms of quality to what they had prior to the pandemic (Figure 4). Approximately $10 \%$ of students found that it was very difficult to implement new teaching techniques, while approximately $64 \%$ of students indicated that certain aspects were difficult. 
Quality of education (during the pandemic) compared to before

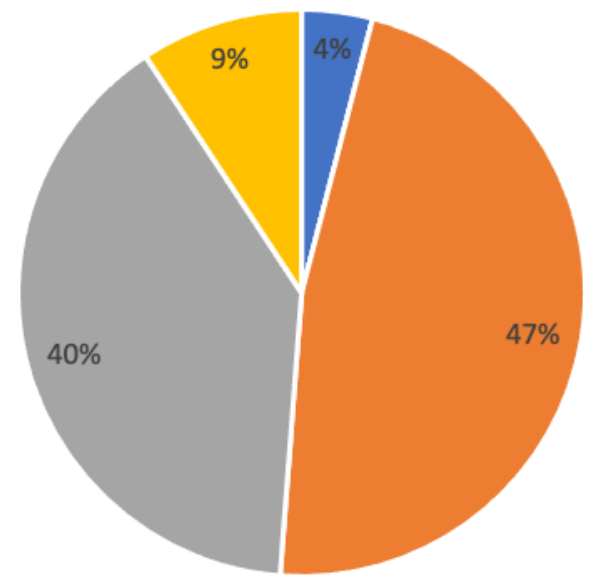

-NO_RESPONSE - Poor $\|$ Same $\|$ Better

Fig. 4. Quality of education during pandemic time

The ratio of material delivered online and face to face learning changed during the pandemic. During the pre-pandemic time, about $60 \%$ of students were using only face-to-face learning, as opposed to the (44\%) who are totally online now. (Figure 5 and Figure 6)

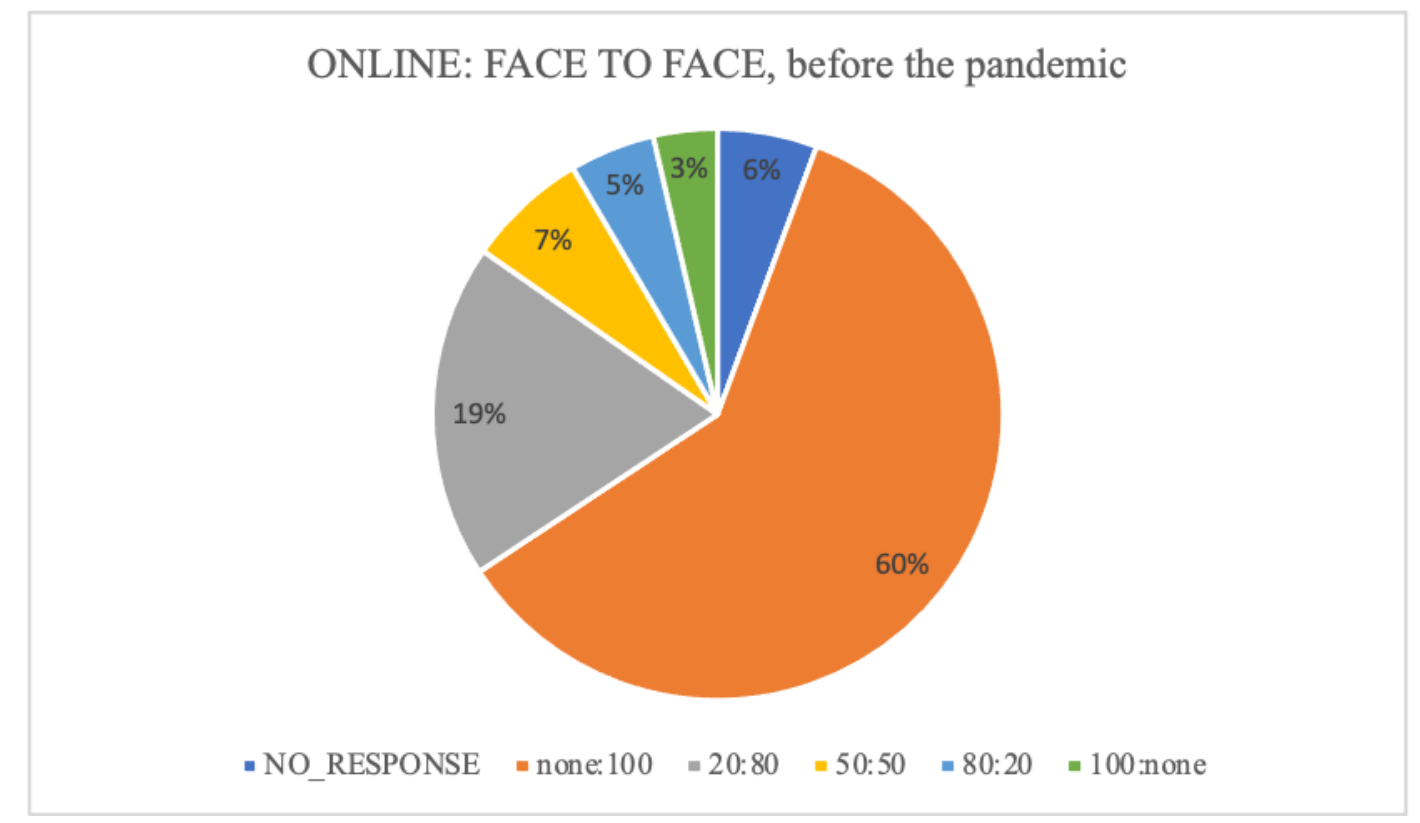

Fig. 5. Online: Face to face learning, before pandemic 


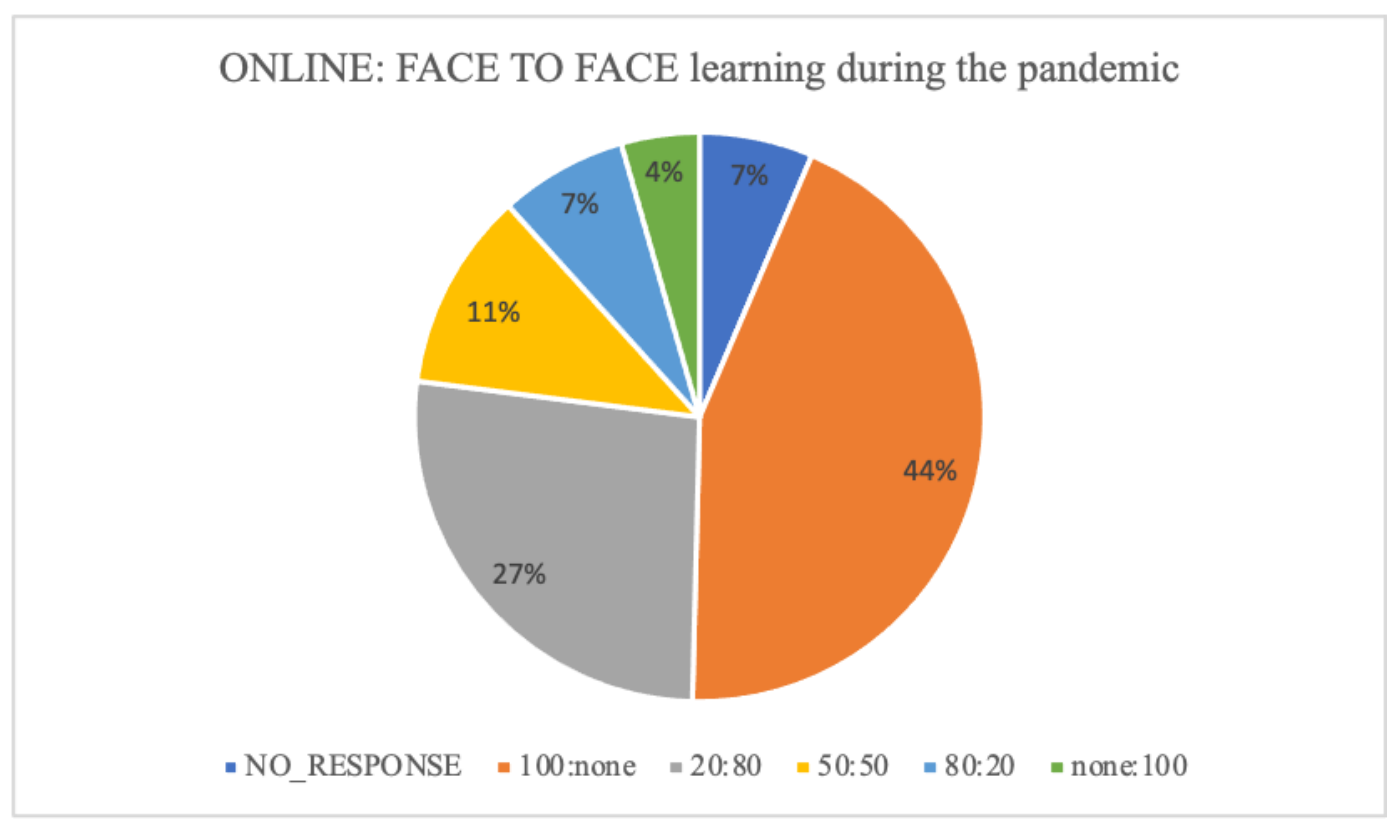

Fig. 6. Online: Face to face learning, during the pandemic

Further, an $88.3 \%$ of participants had exams during the pandemic. Exam formats consisted of either a written paper-based exam or an online viva administered remotely via the internet. These exams were found to be more stressful than previous exam formats.

\subsection{Qualitative study}

\subsubsection{Thematic analysis}

The sub categories that emerged during coding using Grounded Theory (Strauss and Corbin, 1998) are discussed below with supporting statements. The issues surrounding online/ remote learning was a dominant theme that emerged, and its sub-categories are listed in

Table 1.

\section{Positive aspects}

Some students appreciated the new 'virtual' mode of learning as its flexibility, comfortability, availability of recorder material for revisions later. Further, hands on experience with technology, saved the cost of travel and saved extra time for self-study and having more family time were the favorite features highlighted by the students.

'Time wasted on the road die to travelling has reduced.'

'Uniforms are not needed. Traveling time is reduced.'

'Recorded lectures allow time to do it at your own pace and rewind if needed.'

'We can freely study at home.'

'Material more accessible, can be recorded.' 
'Can learn comfortably.'

'Getting used to technology.'

\section{Difficulties}

Though the students liked some of the positive aspects of the online learning many students shared their bad experiences related to it. Major difficulties that could identified were technological deficits or inadequate training for online learning and teaching. Digital poverty, poor efficacy, academic staff lethargy, poor lecture scheduling and time management, lack of interactions with academic staff, and poor peer interaction were the main complaints.

'It a challenge not having a divide between work time and personal time.'

'The poor internet connection interrupts frequently.',

'Internet mobile data is very costly.'

'Completing group work has become very difficult and motivation is lacking.'

'Very hard to do a group project when we can't meet with our group.'

'Couldn't interact with the lecturers on study matters as before.'

'We are forced to learn theories based on practical's, without doing any practical's'.

'Mental stress, eye problem, excessive number of class tests plus assignments.'

'Looking on the laptop screen for 3-5 hours daily is very hazardous to our eyes and mental health.'

'Teachers are not well trained for teaching online.'

'Teachers are not too good in conveying matter with new method.'

Negative attitudes.

The main reason for developing a negative attitude for virtual learning method was technical issues they experience, absence or lack of initial training before shifting to online teaching method. The Teams/Zoom fatigue was an important issue raised by the students due to poor timing of the lectures without adequate breaks. As a result of lengthy online lectures, a distraction was developed among students for certain modules and that is counterproductive . Lack of interaction with teachers and peers does not help.

'Continuous classes with no breaks in between, cannot hold our attention.'

'Struggling to grasp a concept.'

'Anxiety, loss of focus, laziness.'

'Promotes addiction to social media.'

'We missed our humanity, friendship with friends.'

'Couldn't discuss with colleagues.'

'it's too difficult to keep up with the professors and their bunch load of exams.'

'It's easy to fall behind.'

'Pre-recorded lectures feel impersonal, no option to ask questions at the end.'

Need for access to additional resources

The students request some additional resources to cater them during this pandemic time in addition to orientation programme conducted before commencing the online lectures. It seems all most all the selected 
Sri Lankan universities did not conduct such an orientation programme for teaching and learning prior to shift to virtual mode of teaching.

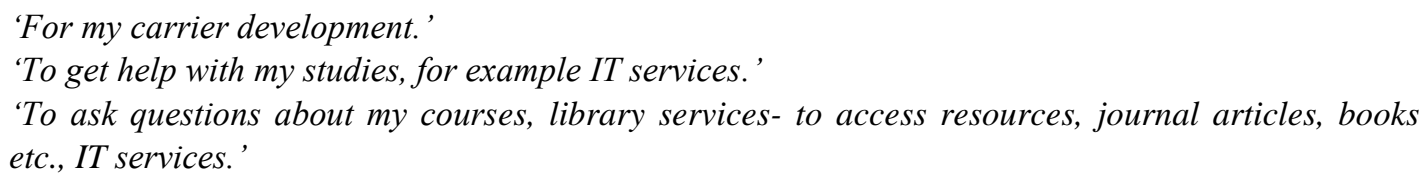

Assessments

According to the comments made by the students for open ended questions designed to get the information on assessments during pandemic time, it was revealed that the students found it difficult to face online exams with the technical incompatibilities, less training on online mode of exams, incompatibilities of the exam with the taught content. However, some of the universities have conducted physical exams though they conducted teaching online. Many of the students still appreciated the physical exams even in the pandemic period with appropriate precautions in terms of health safety.

'Online exams and presentations are not effective enough for proper evaluation.'

'Since no practical knowledge there's no point in doing theory exams.'

'Teacher goes through everything so superficially. What they ask in exams is like from another planet.'

'Allow to come to the campus for exams following health guidelines and PCR done'

'Assessments have been ten times harder.'

'We had practical examinations after online classes.'

'Cheating is easy.'

Suggestions to improve learning online

Many students have made suggestions to improve the effectiveness of the online learning by improving facilities and reducing the costs of data.

'Encourage students to learn outside the local syllabus globally.'

'Improve e-library facilities.'

'Provide students with an easily useable and accessible platform.'

'The interface should be friendlier.'

'Do not restrict but facilitate library access.'

\section{Suggestions to improve examinations online}

The students have addressed some of their burning issues experienced with online examinations which are related to the quality aspect of the assessments. Most of the problems emphasis on lacking facilities for online education. Many of the students request devices (laptops, tabs) and data connections as the students have affording problems and issues in connectivity. These were some of the suggestions from participating students. At the same time some students appreciate the conducting of exams online even with some short comings rather than wasting the time. 
'Need a laptop as it's difficult to do things on smart phones.'

'Offer clear instructions. Stable connection and data packages'

'Yes $i$ wannna tab'

'Yes. Free data bundle'

'To solve data problem need a solution.'

'Need access to good internet.'

'Data support, pre-scheduled fixed exam timetables'

'Pass rate should be increased.'

'Minimize any waiting period to start and end the examination.'

'Reducing duration of a session and a break between two sessions.'

'Providing improved virtual laboratory skill practice programmes.'

'Have camera monitoring in place to ensure that cheating does not occur.'

'It is a relief that we are having exams even in the middle of this pandemic.'

\section{Suggestions to improve distance learning}

Some of the suggestions, ideas and views made by the students to improve the distance learning were truly important and easier to adopt while some of the suggested ways seems to be impractical.

'Conduct only virtual small group discussions.'

'Limiting the sessions to 45 minutes.'

'Make lectures more interactive.'

'Be flexible and lecturers punctual.'

'Better microphones and good training for lecturers.'

'Classes should be live allowing students clarify queries.'

'Lecturers must record the lectures and upload to google classroom.'

'Must upgrade technical issues and must reduce data package charges.'

'Encourage students to put their cameras on for classes.'

Table 1 Thematic views of virtual learning

\begin{tabular}{ll}
\hline Category & Theme \\
\hline Positive aspects & Increased family time \\
& Comfortability and flexibility \\
& Recording facility, enable the student to listen to missed lectures and revisions. \\
& Reduced cost of travel, and time thus saved is useful for self-study \\
& Digital poverty \\
& Psychological impact \\
& Less focus with distraction when studying form home \\
& Less Efficacy in teaching \\
& Less activity \\
& Zoom/Teams fatigue \\
& Lack of facilities \\
& Students and teachers not conversant with online learning \\
\end{tabular}


Lack of practical knowledge

Study and examinations postponed

\begin{tabular}{|c|c|}
\hline \multirow[t]{6}{*}{ Negative attitudes } & Less motivation \\
\hline & Zoom/Teams fatigue \\
\hline & Poor interaction with lecturers and peers \\
\hline & Poor learning efficacy \\
\hline & Unsuitable timetabling and longer exhausting lectures \\
\hline & long-term lethargy was caused by the amount of screen time \\
\hline \multirow{3}{*}{$\begin{array}{l}\text { Why students accessed additional } \\
\text { resources }\end{array}$} & Seek technology resources and assistance \\
\hline & To preserve mental well-being \\
\hline & Poor access to journals or textbooks from library \\
\hline \multirow[t]{3}{*}{ Assessments } & Increased stress \\
\hline & Disparity between teaching and assessment \\
\hline & Increased risk of cheating \\
\hline \multirow[t]{4}{*}{ How to improve online learning } & Facilitate accessibility of library services \\
\hline & More user-friendly software \\
\hline & Improved contact between students and staff \\
\hline & Mitigate digital poverty \\
\hline \multirow[t]{10}{*}{ How to improve online examinations } & Provision of hardware e.g., laptops \\
\hline & Provide a trial exam before the proper exam to make the students familiar with the system \\
\hline & Shorten the format of exams \\
\hline & Proper scheduling of exams with adequate gaps between \\
\hline & Match taught curriculum to the examinations \\
\hline & Restrict the access to unwanted websites during examination time \\
\hline & Install proctoring to reduce cheating \\
\hline & Use user friendly and economic software \\
\hline & Training for lecturers \\
\hline & Proper scheduling of exams with adequate gaps between \\
\hline \multirow[t]{2}{*}{ Post-pandemic continuations } & Record lectures and make them available for revision \\
\hline & Continue online examinations \\
\hline \multirow[t]{4}{*}{ How can we improve distance learning } & Orientation sessions for students and teachers to use digital resources \\
\hline & Introduction of breakout rooms (Zoom) to optimise interaction \\
\hline & effective and productive use of available technology Adopt proven study methods \\
\hline & employed by institutes such as The Open University \\
\hline
\end{tabular}




\section{Discussion}

\subsection{Demographic factors linked to outcomes}

Two hundred and forty-nine students from five universities in Sri Lanka (Kotelawala Defence University, Uwa Wellassa University, Ruhuna University, Sri Jayawardhanepura University and NSBM Green University) participated in our study. And this is close to the representation of females $(78 \%)$ in all universities studied in student communities. The majority of participants in this study (71\%) were 22-25 years of age (Figure 1).

\subsection{Impact on university life}

The findings showed that most students (42\%) are studying online from their homes and own accommodations while $(31 \%)$ of the students remain at boarding places or rented accommodations. Additionally, students who stay at home, enjoyed the extra family time they had. This also minimized their living costs and allowed them to work within safe 'bubbles' instead of being exposed to public.

Group work helps students to develop a range of soft skills; including critical thinking, analytical and communication skills, effective teamwork, appreciation and respect for other views, techniques and problemsolving methods, all of which promote active learning and enhance student learning (Sofroniou and Poutos, 2016). Another study found that group projects were well regarded and encouraged peer interaction (Scribner, Baker and Howe 2003). Therefore, it is important suggestion to increase the group project component especially in this virtual earning system (Rapanta et al., 2020). Further, Rapanta et., al identifies three important elements that are important in online teaching; student-centered design, social activity and peer collaboration (Rapanta et al., 2020).

Most of the students found very challenging to get use to new mode of education. But they had no alternative rather than adapt to changes to continue their studies. Many students reported that the distractions that may occur in their living environment; from home, shared boarding house etc. were a major problem during virtual learning and half of students stated their stress level was higher compared to classroom learning. The main reason behind the increased stress levels was overnight shifting to virtual education as the workload was greater than before.

\subsection{Impact on education}

The classroom education was changed almost overnight to virtual education during the pandemic (Tejedor, Cervi and Tusa, 2020). Students enthusiastically supported the move and appreciated that some elements of distance learning had proved to be successful. The students enjoy the opportunity to personalize their schedules and have convenient access to recorded educational materials like lectures and tutorials (Table 1). Additionally, students claimed limiting online lectures into sessions with short breaks was advantageous. Some studies found that students would like some of these elements of virtual learning to continue even after the pandemic situation went off returns to classroom teaching (Rizun and Strzelecki, 2020). These are important considerations for university administrators in the future as things return to the new 'normal'.

We also identified ongoing issues with new mode of education, virtual learning for university students. Similar observations are not uncommon (Plitnichenko, 2021; Rapanta et al., 2020). Initially, students perceive the quality of teaching to be less than classroom education. Many had difficulties accessing appropriate resource, software, or stable network connections. We observed that currently, more than half of 
the students in participating universities studied online only, and others took a 'combined' learning approach.

Increasingly, technology is being used in education and healthcare, and that is contributing to the need for accessibility. In addition, the problem of digital poverty extends to students in both developing and developed countries regardless of their financial status (Ravselj and Tomazevi, 2020). In the current study, some students complained about the costs associated with data packages and connectivity. As reported in the literature, limited access to resources, connectivity, cost of data and device repair were main complains of the students (Seah, 2020; Shim and Lee, 2020). There is a compelling suggestion for universities to consider offering computers, routers, or handing out free data packages to support students with their academic work and exams (Ravselj and Tomazevi, 2020). This facility is available in some of the universities in England; Kings college London and University of Portsmouth (Kings college London, 2021; University of Portsmouth, 2021). Further Kotelawala Defence University, Sri Lanka has provided a free laptop for every registered student even before the COVID-19 pandemic changes the face-to-face education into almost virtual (Kotelawala Defence University, 2021). Other countries could emulate these measures.

Some students suggested that the universities who are strange to virtual education system need to get the consultation from ethe experts on the distance learning system such as Open University. However, such experienced institutions for distance learning are continue with a 'blended' approach both online and classroom teaching or self-study for selected courses, whereas conventional universities do not (OUSL, 2020). However, consultations with them are likely to be supportive because $47 \%$ of the students in this study thought that the virtual education standard was 'poor. Group work via virtual platforms should be expanded, as it could have positive impacts on mental health and cognitive development of the students (Shim and Lee, 2020).

The objective of all these interventions is to help non-expert university teachers to navigate into online modes of teaching in these challenging times (Rapanta et al., 2020). Further, the students also have suggested to train the lectures to handle online teaching tools effectively and improving their timetabling. When scanning through the literature, it was found that where there is a good access to technology for both academic staff and the students, that has an impact on success of the virtual education system (Nuere and Miguel, 2020). Patience, flexibility, and adaptability are understood to be valuable attributes for academic professionals to use in the development of online education (Nuere and Miguel, 2020). Students in our research $75 \%$ found it difficult to adapt to the modern learning methods Further the lack of interaction between lecturers and students was another issue we observed reported by others too (Rizun and Strzelecki, 2020). Academic personnel must act now to make sure academic staff undergo in-service training and timetabling problems are resolved to encourage engagement and effectiveness of virtual learning.

Furthermore, of the participants, $88 \%$ had exams during the pandemic. Most exam formats used a written paper-based format, a written computer-based format, or a remote viva through the internet. These exams were found to be more stressful than previous exam formats. Previous authors found that those exams conducted during pandemic did not match the taught content (Rizun and Strzelecki, 2020). Students also less familiar to new examination platforms (Rizun and Strzelecki, 2020). They identified important areas for improvement; clarity on the protocols, better access to required software, improved connectivity, practice/sample online exams and proctoring.

As it fails to find a clear end of the COVID-19 pandemic, the online learning only or 'combined' learning will likely to continue further in Sri Lanka. Therefore, it is important to Sri Lankan universities to plan and develop timely solutions to improve online education system considering the student's concerns and views. In that, universities should pay the top priority to improve digital poverty by providing adequate 
resources and training. Also, universities need to work towards improving online examination systems towards the best quality and standard.

\section{Limitations}

Due to the anonymity of this study, it was not possible to verify that all participants were students.

\section{Conclusions}

As there is still no end in sight with the pandemic universities must take proactive action to mitigate predisposing issues related to virtual education. Further, it is important to develop approaches integrating the staff and create plausible examination formats after consultation with experts in online education and distance learning.

\section{Acknowledgements}

I thank Professor Chulananda Goonasekera, Consultant Anesthetist, King's College Hospital, and Kings College London for the contribution made towards this study in all aspects and Dr. Darshana Kottahachchi, Dean and senior lecturer, Faculty of Allied Health Sciences, Kotelawala Defence university for the administrative support given to conduct the study. Finally, I would like to pay my gratitude to all administrative officials of the participating universities in Sri Lanka for assisting in distribution of the questionnaire instrument link to all students.

\section{References}

Kings college London., 2021. Student equipment loans during the 2020/21 academic year. 2021. Retrieved February 11, 2021, from https://self-service.kcl.ac.uk/article/KA-01582/en-us

Kotelawala Defence University., 2021. Undergraduate prospectus 2021. Retrieved February 14, 2021, from https://www.kdu.ac.lk/wpcontent/uploads/2020/012/prospectus.pdf

Scribner, LL., Baker, TL., Howe, V., 2003. Efficacy of Group Projects in Support Skill Acquisition: Student vs. Alumni Perceptions. Marketing Education $\quad$ Review, 13(1), p.59-66. Retrieved https://www.tandfonline.com/doi/abs/10.1080/10528008.2003.11488813

Plitnichenko L., 2021. Online Learning Challenges (\& Ways to Solve Them). Retrieved February 14, 2021, from JellyFish.net website: https://jellyfish.tech/10-challenges-of-e-learning-during-covid-19/

Nuere, S., Miguel, L., 2020. The Digital / Technological Connection with COVID - 19: An Unprecedented Challenge in University Teaching. Technology, Knowledge and Learning, p. 1-13. https://doi.org/10.1007/s10758-020-09454-6

OUSL., 2020. The Open University Sri Lanka. Retrieved January 14, 2021, from https://www.ou.ac.lk/

Rapanta, C., Botturi, L., Goodyear, P., Guàrdia, L., Koole, M., 2020. Online University Teaching During and After the Covid-19 Crisis: Refocusing Teacher Presence and Learning Activity. Postdigital Science and Education, 2(3), p. 923-945. https://doi.org/10.1007/s42438-020-00155-y

Ravselj, D., and Tomazevi, N., 2020. Impacts of the COVID-19 Pandemic on Life of Higher Education Students : A Global Perspective. Sustainability, (January), p.1-34.

Rizun, M., and Strzelecki, A., 2020. Students' acceptance of the covid-19 impact on shifting higher education to distance learning in Poland. International Journal of Environmental Research and Public Health, 17(18), p.1-19. https://doi.org/10.3390/ijerph17186468

Tejedor, S., Cervi, L., Tusa, F., 2020. Education in times of pandemic: Reflections of students and teachers on virtual university education in Spain, Italy and Ecuador. Revista Latina de Comunicación Social, 78, p.1-21. Retrieved from http://nuevaepoca.revistalatinacs.org/index.php/revista/article/view/335 
Shim, TE., Lee, SY., 2020. Children and Youth Services Review College students' experience of emergency remote teaching due to COVID-. Children and Youth Services Review, p.119 (October), 105578. https://doi.org/10.1016/j.childyouth.2020.105578

Sofroniou, A., Poutos, K., 2016. Investigating the effectiveness of group work in mathematics. Education Sciences, 6(3). https://doi.org/10.3390/educsci6030030

Son, C., Hegde, S., Smith, A., Wang, XSF., 2020. Effects of COVID-19 on College Students' Mental Health in the United States: Interview Survey Study. Journal of Medi Internet, 22(9). https://doi.org/10.2196/21279

Strauss, AL., Corbin JM., 1998. Basics of qualitative research : techniques and procedures for developing grounded theory (2nd edition). Thousand Oaks, Sage Publications.

Travis, L., 2010. One of Many Free Survey Tools : Google Docs One of Many Free Survey Tools : Google Docs. Journal of Electronic Resources in Medical Libraries, (October 2011), p.37-41. https://doi.org/10.1080/15424065.2010.482902

University of Portsmouth., 2021. Borrow a laptop for online study. Retrieved February 14, 2021, from https://www.port.ac.uk/study/student-life-in-2020-21/borrowing-equipment-for-online-study 